\title{
Compte rendu de Casse-tête et massues kanak, de Roger BOULAY
}

Isabelle Leblic

\section{(2) OpenEdition \\ Journals}

Édition électronique

URL : http://journals.openedition.org/jso/7313

DOI : $10.4000 /$ jso.7313

ISSN : $1760-7256$

Éditeur

Société des océanistes

Édition imprimée

Date de publication : 15 juin 2015

Pagination : 167-168

ISBN : 9782854301250

ISSN : 0300-953x

Référence électronique

Isabelle Leblic, "Compte rendu de Casse-tête et massues kanak, de Roger Boulay ", Journal de la Société des Océanistes [En ligne], 140 | janvier-juin 2015, mis en ligne le 06 juillet 2015, consulté le 24

septembre 2020. URL : http://journals.openedition.org/jso/7313 ; DOI : https://doi.org/10.4000/jso 7313

Ce document a été généré automatiquement le 24 septembre 2020.

(c) Tous droits réservés 


\title{
Compte rendu de Casse-tête et massues kanak, de Roger BOULAY
}

\author{
Isabelle Leblic
}

\section{RÉFÉRENCE}

BOULAY Roger, 2015. Casse-tête et massues kanak, Igé, Éditions de L'Étrave, 63 p., bibliogr., très nombreuses aquarelles de l'auteur, photographies de Antoine Violleau et reproduction de planches et photographies anciennes.

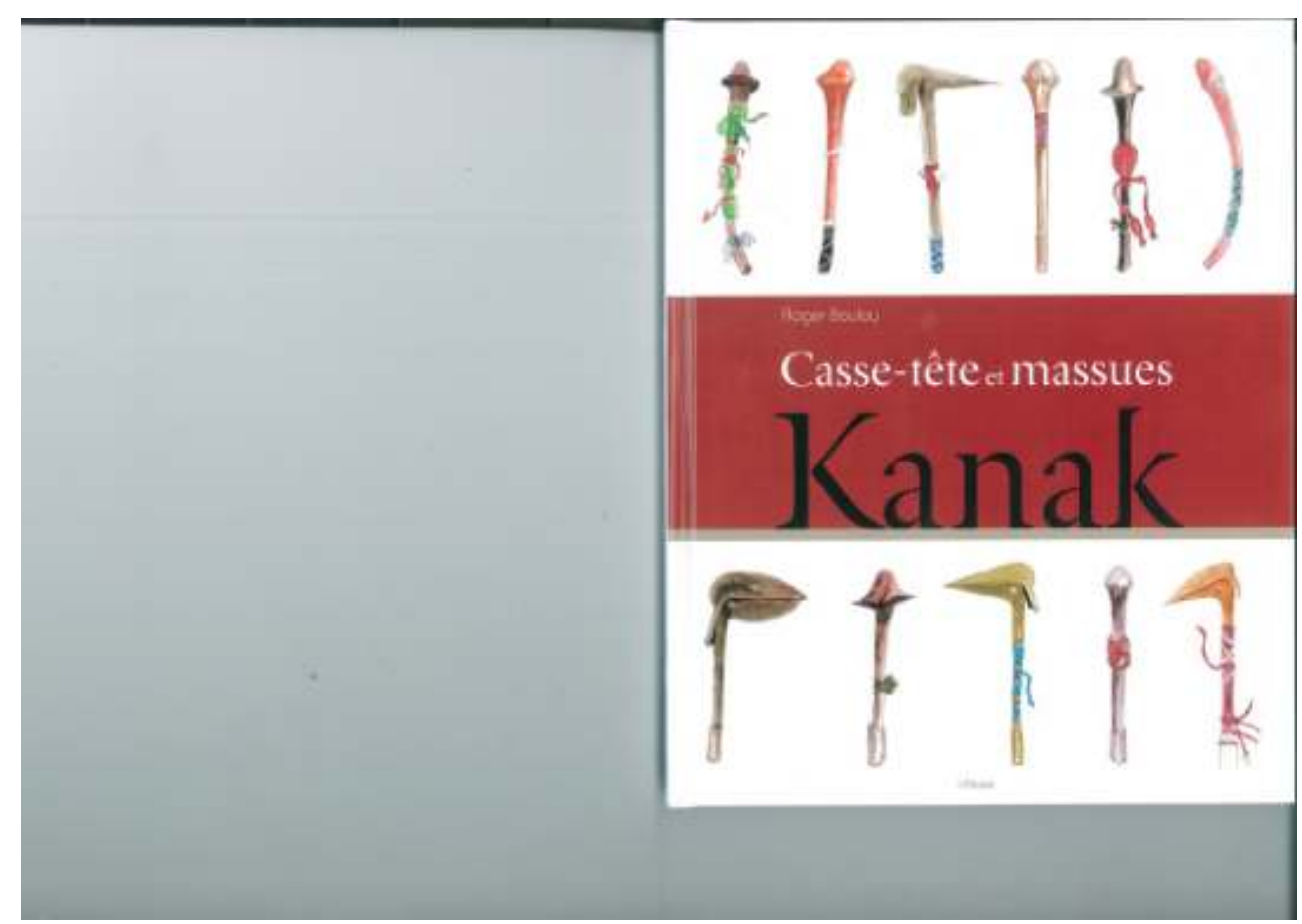

1 Ce petit ouvrage de Roger Boulay sur les casse-tête et massues kanak, joliment illustré et mis en page, présente la grande richesse des collections publiques et privées en la 
matière. Outre la reproduction d'anciennes planches photographiques ou de dessins, les pages reproduisent de nombreux extraits des carnets de dessins et aquarelles de l'auteur, donnant à ce livre un cachet tout particulier. Roger Boulay, qui a réalisé l'inventaire du patrimoine kanak dispersé durant de plusieurs années (IPKD 2011-2014), a parcouru 54 musées de France et d'Europe pour répertorier 12000 objets kanak qui y sont présents et réalisé 3700 fiches détaillées à destination des chercheurs et du public intéressé. Il nous présente ici un volet de cet inventaire augmenté d'autres collections publiques (une centaine de musée) ou privées, à partir de ces carnets de croquis aquarellés, de photographies d'objets provenant de deux collections individuelles (Nantes et Nice, sans doute de Jean-Yves Coué et Thierry Mackie remerciés en fin d'ouvrage) et de recherches bibliographiques. Cela nous permet de nous rendre compte de la grande richesse de ce monde des casse-tête et massues, de ces armes kanak, dont les premières collectes furent réalisées par James Cook en 1774.

2 Ainsi, le premier chapitre (pp. 2-9) nous plonge dans le monde des voyageurs et des collectionneurs. Il nous présente rapidement la collecte de la période coloniale, les trafiquants. Roger Boulay revient sur le fait que si les massues sont les plus présentes dans les collections, elles sont aussi les moins documentées, "orphelines de leur histoire" (p. 6). Le deuxième chapitre traite des "Techniques et matériaux" (pp.11-13), en reprenant les éléments que l'on trouve dans des écrits plus anciens qui sont croisés avec les données recueillies lors de l'IPKD. Puis viennent les «Types de massues et casse-tête » (pp. 14-50) qui constituent le cœur de l'ouvrage avec près de 40 pages richement illustrées. On peut noter "trois formes rares et anciennes", peu courantes, que sont le casse-tête pioche, la massue bi-pointe et massue à palette qui viennent compléter les célèbres massues phallomorphes et longiformes et casse-tête dits « bec d'oiseau » (p. 15).

Enfin, le dernier chapitre présente les "Éléments associés: pouvoir et prestance " (pp. 50-62):

«On peut affirmer que toutes les massues qui auraient été collectées directement des mains de leurs possesseurs devaient porter des bouquets de végétaux, liés au manche par des cordonnets de poils de roussettes, des bandes de tapa ou des fragments de nattes en pandanus et des étoffes d'origine européenne. » (p. 51)

Tous ces éléments, restés longtemps inaperçus, sont porteurs de magies, de pouvoir et donnent en grande partie l'efficacité à l'arme et au bras qui la tient. Comme tout domaine technique kanak, l'introduction d'éléments allogènes ont été très rapidement intégrés à la confection des objets, ici des cotonnades et des andrinoples (d'étoffes de coton teinte en rouge). Pour conclure, Roger Boulay revient sur le fait que beaucoup reste à faire pour tout connaître tant des bois utilisés que des maniements, "des entrainements, coups et bottes secrètes des guerriers kanak » (p. 62).

Ouvrage à recommander pour toute personne s'intéressant aux arts kanak. 